\title{
A FORMAÇÃO DE PROFESSORES PARA EDUCAÇÃO DO CAMPO: UMA EXPERIÊNCIA NA DISCIPLINA "CAMPOS NUMÉRICOS"
}

\author{
Daniel Fernando Bovolenta Ovigli*
}

\begin{abstract}
RESUMO: A formação de professores para educação do campo configura-se como política pública que vem tomando corpo na última década, especialmente após a Resolução CNE/CEB nำ1, de abril de 2002, que institui as diretrizes operacionais para educação básica do campo. Em 2006 surgem as primeiras experiências de oferta de licenciaturas em educação do campo com habilitações em ciências da natureza e matemática, áreas que historicamente apresentam número insuficiente de professores para o atendimento à demanda no país. Essas licenciaturas apresentam uma proposta diferenciada, uma vez que formam professores por áreas do conhecimento, a exemplo das Ciências da Natureza e Matemática, assumindo um desenho curricular considerado inovador. A pedagogia da alternância, empregada em cursos dessa natureza, é também um diferencial, na medida em que parte significativa dos licenciandos já é atuante em escolas do campo. Considerando-se serem recentes, há reduzido número de produções acadêmico-científicas sobre tais habilitações no contexto das Licenciaturas em Educação do Campo. Diante da conjuntura acima exposta, apresentamos uma experiência desenvolvida na Universidade Federal do Triângulo Mineiro (UFTM), em uma disciplina intitulada "Campos Numéricos", ofertada para o primeiro semestre do curso em questão. O artigo apresenta uma breve conjuntura da educação do campo no país, as licenciaturas nessa área, focalizando as habilitações em Ciências da Natureza e Matemática, e finaliza relatando a experiência desenvolvida.
\end{abstract}

Palavras-chave: Educação do campo; Formação de professores; Educação matemática.

ABSTRACT: Teacher training for rural education is configured as public policy that is taking shape in the last decade, especially after the Resolution CNE/CEB no 1, April 2002 , that establishes the operational guidelines for basic education in rural areas. The firsts undergraduate courses in this area was offered in 2006, with majors in natural sciences and mathematics, areas that historically have insufficient number of teachers to supply the demand in Brazil. These undergraduate courses have different proposals, since they form teachers by knowledge areas, assuming a curriculum design considered innovative. The pedagogy of alternation, used in courses of this nature, it is also a differential. Considering be recent, there are few academic-scientific production about these majors in the rural education context. Given the scenario exposed above, we present an experience developed at the Federal University of Triângulo Mineiro (UFTM) in a discipline entitled "Numerical Fields", offered for the first semester in that course. The article presents a brief scenario of rural education in Brazil, the degrees in this area, focusing the major in Natural Sciences and Mathematics, and finish reporting the developed experience.

Keywords: Rural education; Teacher education; Mathematics education.

\footnotetext{
Doutor em Educação para a Ciência pela Universidade Estadual Paulista "Júlio de Mesquita Filho" (Unesp) - Campus de Bauru. Professor do curso de Licenciatura em Educação do Campo - habilitações em Ciências da Natureza ou Matemática junto à Universidade Federal do Triângulo Mineiro (UFTM). E-mail: daniel@icene.uftm.edu.br
} 


\section{INTRODUÇÃO}

\section{Contexto histórico e definições}

Em uma breve retrospectiva histórica acerca da educação brasileira verifica-se que, nos primeiros quatro séculos de sua formação social, não se demandava a qualificação da força de trabalho, gerando certo descompromisso, por parte das elites dirigentes, em relação ao aprendizado escolar das camadas populares (RIBEIRO, 2012). Mesmo havendo iniciativas de educação rural ${ }^{1}$ ainda no século XIX, é a partir da década de 1930 que tem início um modelo de educação voltado a essa modalidade.

No entanto, em meados dos anos 1980 é que se intensificam ocupações de terra e marchas para pressionar a reforma agrária no país. Nessa década emergem movimentos sociais da terra em defesa do acesso à educação pública, gratuita e de qualidade para a população do campo, em todos os níveis. A constituição de uma educação básica do campo foi pensada posteriormente e vai se configurando nesse aprendizado em que os trabalhadores do campo se percebem diferentes e reconhecem a importância da luta para a sua formação. No entanto, nem sempre transferem para as práticas escolares de seus descendentes a compreensão que têm do valor da conquista da terra e de uma política agrícola que lhes seja conveniente. Aparece aqui com muito realismo a relação entre a luta pela terra e a luta pela escola (ARROYO; FERNANDES, 1999).

Segundo Caldart (2003), a escola não é uma prioridade inicial na luta dos trabalhadores do campo e sem-terra; trata-se de uma exigência que se impõe pela realidade das crianças em idade escolar que acompanham os pais durante as ocupações e nas perguntas dessas crianças e desses pais sobre 0 futuro dos mais jovens.

A educação oferecida no campo se diferencia da educação efetivada nas cidades não exatamente em seus conteúdos, pois necessita também fornecer todo o suporte teórico-conceitual trabalhado por uma escola urbana.

\footnotetext{
1 Um modelo de educação rural pode ser definido como educação urbana que se processa na zona rural. A educação do campo, ao contrário, considera as especificidades da população residente nessas áreas, seus saberes e fazeres.
} 
Entretanto, necessita atuar de forma diferenciada, estabelecendo relações com a realidade dos sujeitos da aprendizagem. Trata-se de levar para o interior da instituição escolar elementos que sirvam para reflexão, bem como apresentar potencial para transformar a realidade na qual vivem. Pela ação dos movimentos sociais, foram surgindo propostas e diretrizes para uma educação no campo voltada e pensada para as pessoas do campo (BRASIL, 2008).

Pensar em uma educação para o campo é pensar em uma educação que valorize e entenda o histórico dos atores sociais envolvidos, de modo a entender a própria história, contextualizar os acontecimentos e, acima de tudo, respeitar a realidade local, suas especificidades e suas necessidades.

Ribeiro (2012) afirma existirem três aspectos que marcam a diferença essencial entre a educação rural tradicional, no campo, e a proposta de uma educação básica do campo. Esta última vem sendo construída em conjunto, pelos agricultores familiares e por educadores e assessores ligados aos movimentos sociais do campo e a instituições que congregam e/ou apoiam agricultores familiares:

a) o modelo de educação tradicional rural é vinculado com o sistema capitalista de produção e de sociedade. Assim, fundamenta-se no dualismo campo/cidade e na exploração da força de trabalho; já a proposta de educação básica do campo não está pronta, não é fechada, nem é imposta: está sendo construída por vários setores envolvidos com a educação (trabalhadores, educadores, técnicos, etc.);

b) apresentam finalidades distintas: enquanto a escola rural está comprometida com a lógica da produtividade, a escola do campo pensa na formação do cidadão do e no campo, com competência para enfrentar os desafios da produção e da vida contemporânea;

c) currículo, objetivos e metodologias também são distintos: na escola rural estão direcionados para o sistema capitalista; para a escola básica do campo a memória das lutas e das experiências produtivas constitui-se em base 
curricular. Assim, além dos conhecimentos científicos, a escola do campo reflete acerca das experiências de seus atores sociais.

Portanto, é essencial o entendimento dessas diferenças para que seja possível instituir uma educação de qualidade no e do campo. Também se faz necessário que os educadores, técnicos, diretores e agentes educacionais observem esta modalidade com suas particularidades e trabalhem no sentido de aproveitá-las para que o processo de ensino-aprendizagem se dê de forma rica e significativa para todos os educandos e educadores. Busca-se, pois, uma escola humanitária que promova a formação não apenas de cidadãos, mas também de sujeitos transformadores da realidade em que vivem.

A educação do campo como política pública: fazendo caminho ao caminhar

A gênese da educação do campo institucionalizada como tal no país passa por sua contextualização dentro da política do Governo Federal, em seu Programa Nacional de Educação na Reforma Agrária (PRONERA).

O PRONERA foi criado em 1998, por meio da portaria nำ10/98 do então Ministério Extraordinário de Política Fundiária, sendo vinculado diretamente ao Gabinete do Ministro e executado pelo Instituto Nacional de Colonização e Reforma Agrária (INCRA), no Ministério do Desenvolvimento Agrário (MDA). Tem como objetivo ampliar os níveis de escolarização formal dos trabalhadores e trabalhadoras da Reforma Agrária e tem se tornado um relevante instrumento de democratização do conhecimento no campo, uma vez que propõe e apoia projetos de escolarização formal em todos os níveis de ensino.

O surgimento deste programa se deu com a reivindicação organizada dos movimentos sociais do campo e concretiza-se por meio da parceria estabelecida entre eles, o governo federal e as instituições de ensino superior. No biênio 2003 - 2004, o PRONERA firmou convênio com diferentes universidades e organizações de assentados e do meio rural, visando ampliar suas ações. Foram assinados 27 convênios para o então Ensino Médio Normal, tendo em vista formar professores para atuação na educação infantil e 
anos iniciais. Projetos voltados à profissionalização em outras áreas também se expandiram, chegando à agropecuária, enfermagem e administração de cooperativas, por meio de outros 15 novos convênios (BRASIL, 2014).

No âmbito do ensino de graduação, o PRONERA firmou novas parcerias com universidades e institutos de pesquisa tendo em vista formar profissionais nas áreas de Pedagogia da Terra, História, Geografia, Ciências Agrárias e Agronomia, em um total de 13 novos convênios para atender assentados de áreas reformadas do país (BRASIL, 2014).

Trata-se do embrião das propostas de cursos intitulados "Licenciatura em Educação do Campo", específicos para a população assentada, professores em exercício nas escolas do campo da rede pública. Também contempla outros profissionais da educação com atuação em experiências educacionais alternativas de educação do campo, em programas governamentais que visem à ampliação do acesso à educação básica da população do campo, além do público jovem e adulto residente nessas comunidades. O curso, portanto, se justifica e tem sua relevância pelas demandas colocadas pela realidade social do Brasil rural, no qual a necessidade de formação profissional de seus habitantes vem sendo reconhecida. A proposta também se fundamenta no pressuposto de que a história e a cultura das comunidades do campo são os pontos de partida para qualquer proposta educativa e de pesquisa a ser desenvolvida nessas comunidades (ARROYO; FERNANDES, 1999).

As propostas pedagógicas dos cursos de Licenciatura em Educação do Campo empregam como perspectiva de desenvolvimento o regime de alternância, sistema criado na França, na década de 1930 do século XX. Voltava-se ao atendimento escolar dos filhos de agricultores frente às defasagens educacionais de ensino do meio rural e do desinteresse desses jovens pela escola tradicional, não contextualizada com as especificidades do campo. A pedagogia da alternância, como é chamada, consiste em uma articulação entre dois tempos educativos - o tempo escola (TE) e o tempo comunidade (TC). No TE o educando permanece no espaço da universidade em regime de internato $\mathrm{e}$, no $\mathrm{TC}$, o educando retorna à sua comunidade de origem para colocar em prática as questões que foram objeto de estudo no TE. 
Ademais o licenciando leva, como tarefa, textos próprios do TE, para estudos. Trata-se de uma organização de ensino diferenciada, que articula teoria e prática em espaços-tempo distintos exigindo do formador, e também dos licenciandos, itinerários formativos específicos que não tem sido considerada nos cursos de formação de professores em geral (OLIVEIRA, 2010).

\section{AS LICENCIATURAS EM CIÊNCIAS DA NATUREZA E MATEMÁTICA NO CONTEXTO DA EDUCAÇÃO DO CAMPO}

Os eventos e movimentos anteriores à realização do II Seminário de Educação do Campo de 2004, ocorridos em todo o Brasil, significaram um marco na ampliação do debate participativo por uma política específica dedicada à formação de professores do campo.

Dessa forma, os anos posteriores a 2004 caracterizam-se como período próspero no que diz respeito aos avanços na institucionalização de políticas de formação docente para as escolas do campo, bem como do fortalecimento do PRONERA. Esse programa, como mencionado, fomentou a implantação de vários cursos de formação de educadores do campo em diferentes regiões do país, a exemplo dos cursos de Pedagogia da Terra; Pedagogia das Águas; Licenciaturas em Geografia, História, Letras e Artes (TAFFAREL et al., 2011).

Pio (2011), em sua dissertação de mestrado sistematiza marcos e movimentos para construção e implementação do programa de formação de educadores para o campo:

- II Seminário de Educação do Campo (2002)

- II Conferência Nacional por uma Educação do Campo (II CNEC) (2004)

- Criação da Coordenação Geral de Educação do Campo no Ministério da Educação (MEC) (2005)

- Criação de uma Coordenação Geral de Educação do Campo no Instituto Nacional de Colonização e Reforma Agrária (INCRA)/Ministério do Desenvolvimento Agrário (MDA) (2006)

- Seminários Estaduais de Educação do Campo promovidos pelo MEC em praticamente todos os estados brasileiros, nos anos de 2005 e 2006 
- Realização de dois Seminários de Pesquisa em Educação do Campo (2005 e 2008)

- Criação do Programa "Saberes da Terra" (2005)

- Criação do Programa PROCAMPO - Licenciatura em Educação do Campo (2006)

Também é possível considerar diversas iniciativas por parte de secretarias estaduais e municipais de educação, dos movimentos sociais e das universidades, que representam um ciclo de ações de afirmação da Educação do Campo no interior da estrutura do Estado, notadamente no Poder Executivo, tanto quanto no interior da sociedade civil e nas instituições educacionais.

Estatísticas relativas a essas ações também expressam o que vem sendo desenvolvido. De acordo com o Instituto de Pesquisa Econômica Aplicada (IPEA), dados de 2010 apontavam que 82,22\% dos jovens de 15 a 17 anos frequentavam a escola, porém apenas $52,18 \%$ estavam matriculados no Ensino Médio. Observava-se, também, uma queda no número de matrículas nesse nível de ensino nas regiões Centro-Oeste, Sul e Sudeste a partir de 2005. Estatísticas do Censo Escolar também de 2010 informam que, nessa mesma faixa etária (15-17 anos), apenas 36\% dos jovens estavam no Ensino Médio. Essa situação era ainda mais agravante no meio rural: pouco mais de um quinto dos jovens nessa faixa etária cursava o Ensino Médio. Dentre os professores dos anos finais do Ensino Fundamental e do Ensino Médio, 43,76\% apresentavam como titulação o Ensino Médio ou equivalente e apenas pouco mais de $50 \%$ possuíam habilitação legal para o ensino, a licenciatura.

A Pesquisa Nacional de Educação na Reforma Agrária - PNERA (BRASIL, 2007) apontou que, dentre as 8.679 escolas em assentamentos, apenas 373 ofereciam o Ensino Médio. A escassez e a falta de formação de professores encontram-se entre os vários fatores responsáveis por esse quadro, o que motivou a criação e disseminação dos cursos de Licenciatura em Educação do Campo - habilitações Ciências da Natureza e Matemática, em especial, por todas as regiões administrativas do país.

Informações divulgadas pelo Instituto Nacional de Estudos e Pesquisas Educacionais Anísio Teixeira (INEP) em 2010, afirmavam faltar por volta de 
235 mil professores para o Ensino Médio no país, principalmente nas áreas de Ciências da Natureza e Matemática. O estudo também indicava uma carência em relação à oferta para a segunda etapa do Ensino Fundamental (6ำ ao 9o ano) nos assentamentos (BRASIL, 2007). Em relação ao Ensino Médio, é possível afirmar que são poucas as escolas dos assentamentos que oferecem esse nível de ensino aos estudantes: apenas 4,3\% das escolas nacionais e 8,8\% das escolas da Região Sudeste (região de atuação da universidade na qual a presente proposta foi desenvolvida) são localizadas em assentamentos.

Em 2004, por exemplo, 61.344 alunos da Região Sudeste (assentados) frequentavam a escola básica; esse percentual corresponde a 34,0\% da população assentada. Os anos iniciais do Ensino Fundamental eram ofertados em $73,9 \%$ das escolas (24.301 estudantes), e os anos finais ( $5^{\text {a }}$ a $8^{\text {a }}$ série) em $42,7 \%$ das escolas (20.026 estudantes); apenas 8,8\% das escolas estudadas ofertavam o Ensino Médio (5.963 estudantes). Esses dados indicam que as escolas dos assentamentos não ofertavam o Ensino Médio de forma ajustada à demanda. Daí ser circunstância natural que os alunos dos assentamentos não frequentassem o Ensino Médio, por falta de oferta das próprias escolas.

Ainda segundo a PNERA, há carência de oferta dos anos mais elevados da educação básica nas escolas do campo, já que estas oferecem apenas os anos iniciais do Ensino Fundamental. Tal situação ocasiona não apenas o atraso escolar, mas também explica o êxodo rural dos jovens estudantes.

$\mathrm{Na}$ Região Sudeste, também há muitos jovens fora da escola (BRASIL, 2007). As razões, de acordo com as famílias, incluem a distância da escola $(45,4 \%)$, inexistência de turmas adequadas ao nível escolar dos alunos $(17,3 \%)$, ausência de escola no assentamento $(18,7 \%)$, falta de vagas $(23,5 \%)$ e o pouco interesse das crianças pela escola $(31,9 \%)$.

O documento citado também evidencia o número relevante de professores atuantes nos anos finais do Ensino Fundamental e no Ensino Médio que não apresentam formação em nível superior, contrariando a legislação em vigor: a situação se torna mais grave nos pequenos municípios, nas periferias das grandes cidades e na zona rural propriamente dita.

A esse respeito, as Diretrizes Operacionais para a Educação Básica do Campo (promulgadas pela Resolução CNE/CEB 01, de 03 de abril de 2002) 
sinalizam a necessidade de se repensar a organização da escola, do conhecimento e da prática pedagógica. Estabelece que o currículo e a aprendizagem são relacionados ao trabalho e à diversidade do campo em todos os seus aspectos: sociais, culturais, políticos, econômicos, de gênero, geração e etnia (BRASIL, 2002), o que implica pensar caminhos alternativos para a formação dos educadores do campo.

A exequibilidade desse projeto de Escola do Campo passa pelo compromisso de conhecer e incorporar as necessidades do campo e a relação delas com o conhecimento socialmente produzido e demandado pelos seus sujeitos. Esse contexto exige profissionais que sejam capazes de romper com a visão disciplinar, estreita e fragmentada que orienta, em geral, os cursos de formação docente no país, especialmente nas áreas de Ciências da Natureza e Matemática. Trata-se de pensar e de levar adiante uma organização do trabalho pedagógico baseada em uma visão mais abrangente e integrada de sociedade, natureza e homem (LIMA et al.,2009).

As diretrizes supracitadas destacam a necessidade de se refletir sobre uma concepção de escola, de aprendizagem e de formação de educadores que seja capaz de entender as demandas apresentadas pela população do campo, incluindo assentados da Reforma Agrária, agricultores familiares e camponeses. Documento com a proposta de um Plano Nacional de Formação dos Profissionais da Educação do Campo, elaborado por Grupo de Trabalho do Ministério da Educação (MEC), afirma (BRASIL, 2009, p.2):

A formação do profissional é um desafio que tem a ver com o futuro da educação básica do campo. (...) para superar os desafios, e possibilitar a atuação de profissionais qualificados dentro dos princípios políticos pedagógicos já apontados nas escolas do campo, a preparação do professor precisa ser mais ampla, extrapolando a estrita formação por disciplinas que hoje predomina nos cursos de licenciatura.

É, pois, nesse contexto, que se reforça o incentivo à efetivação de uma licenciatura específica para a Educação do Campo, com respaldo na Resolução nº 3/1997, do Conselho Nacional de Educação (CNE). Especialistas vinculados às universidades e aos movimentos sociais são chamados a 
colaborar, apresentando ao MEC uma proposta concreta de formação de educadores do campo, construída nesses novos elementos acima caracterizados. No início do ano de 2006, como mencionado no histórico acima, o grupo de trabalho constituído apresentou a proposta de criação de um curso de "Licenciatura Plena em Educação do Campo" para formação de educadores voltados à atuação na Educação Básica em escolas do campo. Estes cursos seriam mantidos por Instituições de Ensino Superior (IES) interessadas em participar do projeto, com apoio e/ou parceria institucional do MEC.

Nessa fase tem início o Programa de Apoio à Formação Superior em Licenciatura em Educação do Campo (Procampo), que apoia a implementação de cursos regulares de Licenciatura em Educação do Campo nas instituições públicas de Ensino Superior de todo o país. Essas ofertas focaram-se na formação de educadores para a docência nos anos finais do Ensino Fundamental e Ensino Médio nas escolas do campo, agrupadas em áreas, dentre as quais Ciências da Natureza e Matemática, como duas habilitações prioritárias face à carência de professores habilitados para ambas as áreas. Quatro universidades iniciaram, em 2008, as turmas-piloto, sendo elas: Universidade de Brasília (UnB), Universidade Federal de Minas Gerais (UFMG), Universidade Federal da Bahia (UFBA) e Universidade Federal de Sergipe (UFS) (ANTUNES-ROCHA, 2009; LIMA et.al., 2009).

$\mathrm{Na}$ atualidade, tais habilitações desenvolvem-se em 27 (vinte e sete) instituições de Ensino Superior no território nacional. As turmas, em geral, ofertam 60 vagas e um vestibular especial, para atender às habilitações; têm uma duração de oito semestres, quando ao seu término são apresentados os Trabalhos de Conclusão de Curso, fechando assim o oitavo tempo-escola e comunidade.

Diante do contexto atual da Educação do Campo, estudantes, professores e coordenadores das áreas de formação se veem dentro de um processo de construção de uma nova concepção de educação e de campo (PIO, 2011).

Essa experiência, portanto, possibilita conhecer outras realidades, muito diferentes daquelas relativas ao modelo de educação urbana e, por isso, 
constitui-se como um campo novo de proposição, realização e pesquisa. Iniciativas mais recentes acerca dessas questões foram iniciadas por meio de recursos fornecidos a partir do edital de seleção no 02/2012 SESU/SETEC/SECADI/MEC ${ }^{2}$, de 31 de agosto de 2012 e fomentaram, centralmente, a criação de habilitações em áreas de Ciências da Natureza e Matemática nas Licenciaturas em Educação do Campo.

Considerando-se os fatores acima elencados, pouco se sabe sobre aquilo que efetivamente é realizado enquanto práticas de formação de professores para educação do campo no país. É necessário discutir, de forma ampla e adequada, esse perfil de formação junto aos demais setores e/ou grupos sociais, em especial àqueles tratados nos estudos, como subsídio à formulação e avaliação de políticas públicas. No bojo do edital supracitado a Universidade Federal do Triângulo Mineiro (UFTM), situada em Uberaba/MG, apresentou uma proposta e iniciou a oferta desse novo curso de graduação em julho de 2014, referenciado como "LECampo" junto à universidade.

Tendo em vista trazer elementos para reflexão, fundamentados em práticas pedagógicas vivenciadas junto a esse curso, buscamos apresentar uma experiência de trabalho desenvolvida no primeiro TE, componente curricular intitulado "Campos Numéricos", ofertado a ambas as habilitações Ciências da Natureza e Matemática.

\section{RELATANDO A EXPERIÊNCIA: A DISCIPLINA “CAMPOS NUMÉRICOS” NA LECampo/UFTM}

A turma na qual a intervenção aqui apresentada foi desenvolvida constitui-se por 23 estudantes atuantes em escolas do campo, ainda que não necessariamente sejam assentados da reforma agrária. Desse total, 13 atuam na educação básica (educação infantil e anos iniciais), sendo um deles professor de filosofia. Uma estudante é oriunda de Novo Cruzeiro, município situado na região norte de Minas Gerais, e um provém de Nova União, estado de Rondônia. Destaque-se que o conteúdo programático previsto para a

\footnotetext{
2 Secretaria de Educação Superior / Secretaria de Educação Profissional e Tecnológica / Secretaria de Educação Continuada, Alfabetização, Diversidade e Inclusão/Ministério da Educação.
} 
disciplina apresenta duração de 90 horas-aula (sendo 60 horas de tempoescola e 30 de tempo-comunidade).

Apresentar para o estudante o sistema de numeração atual, denominado indo-arábico, sem explicitar sua construção histórica parece não ter sentido, uma vez que se faz necessário compreender como tal sistema surgiu e se desenvolveu, estabelecendo-se socialmente. Entendemos que uma forma de trabalhar esse conceito nas aulas de matemática, de uma forma mais dinâmica e interessante, é iniciar por meio do estudo dos sistemas de numeração empregados pelos povos antigos, especialmente suas representações e sua base (quantidade de símbolos utilizados para escrever todos os numerais desse sistema). Desse modo, tendo como fio condutor a história de alguns sistemas de numeração antigos, é que desenvolvemos atividades que permitissem aos licenciandos compreender o sistema de numeração atual. Dessa forma, buscávamos favorecer a compreensão do sistema de numeração decimal por meio dos sistemas de numeração dos povos antigos.

A esse respeito, a história da matemática nos apresenta os sistemas antigos de numeração utilizados por diversos povos, dentre eles os babilônios, egípcios, romanos, gregos e maias. A forma como esses sistemas foram surgindo está diretamente ligada à necessidade de contar ou relacionar. Para alguns historiadores a ideia de contar surgiu em épocas primitivas, quando 0 homem passa a se dedicar às atividades agrícolas e de pastoreio, evidenciando inúmeras interfaces com o campo.

Segundo Eves (2004), quando o homem primitivo começou a perceber a necessidade de contagem de seu rebanho, ele iniciou o desenvolvimento de uma forma de quantificar. Segundo o autor, é provável que a maneira mais antiga de contar se baseasse em algum método de registro simples, empregando o princípio da correspondência biunívoca: a ideia de relacionar cada carneiro do rebanho com uma pedra, ou um nó em cordas, riscos nas pedras ou em ossos: assim, tinham a correspondência um a um.

Em função da necessidade de efetuar contagens mais extensas, se fez necessária a evolução da ideia de contagem, levando os povos antigos a desenvolver seus sistemas de numeração para facilitar seus cálculos. A história desses sistemas de numeração nos permite observar que estavam 
relacionados com símbolos do seu cotidiano, como no caso dos egípcios, que utilizavam partes do corpo ou a representação de animais e utensílios do dia-adia. Assim, entendemos que a cultura dos povos influenciou significativamente a construção de seus sistemas de numeração (JUCÁ; FARIAS-JR.; SÁ, 2011).

O homem primitivo, com os dedos, constituía um dispositivo de correspondência conveniente: assim, não é de se estranhar que o número dez acabasse sendo escolhido frequentemente como base. Entretanto, o sistema quinário, ou sistema de numeração de base cinco, foi o primeiro a ser usado extensivamente (EVES, 2004).

Frente a tais pressupostos, Campos Numéricos teve início com os seguintes objetivos: (i) situar historicamente os números e a importância dos diversos povos na construção desse conceito, focalizando a numeração egípcia, babilônica, grega e romana, (ii) reconhecer a existência de outros sistemas de numeração, (iii) criar um sistema de numeração próprio e, a partir desse produto, refletir sobre os limites e as possibilidades dessa produção, (iv) apresentar as diferentes possibilidades para representar um número: destacamos a ação prevista no objetivo (iii).

Em um primeiro momento (teórico), problematizamos oralmente a definição de número, seus usos cotidianos e como a sociedade chegou ao atual sistema de numeração (indo-arábico), além de abordar as operações aritméticas no campo dos números reais. A discussão foi conduzida com a utilização da referência abaixo, adaptada especialmente para o trabalho nessa aula, bem como nas três aulas seguintes:

SOUZA, Eronildo de Jesus. Sobre a história dos números. Disponível em <http://www.ifba.edu.br/dca/Corpo Docente/MAT/EJS/SOBRE A HISTORIA DOS NUMEROS.pdf>. Acesso em 20 abr. 2014.

Em um segundo momento (prático), os licenciandos foram convidados a construir um sistema numérico. Para tal, fizeram uso de sulfite colorido, palito de fósforo, fita de cetim, cordão, feltro, EVA, papel camurça, cartolinas, revistas e jornais para recorte, canetas hidrocor, lápis de cor, guache, barbantes coloridos, cola, tesoura e "sucatas". A Figura 1 apresenta os sistemas de 
numeração desenvolvidos pelos licenciandos. Ao término da atividade relataram, em uma roda de conversa, as características (nome, símbolos, valores, etc.), exemplos de uso, a forma de construção dos conjuntos (incluindo características presentes nos sistemas de numeração dos povos tratados no texto empregado como referência para a aula) e as dificuldades encontradas no processo criativo/lógico.

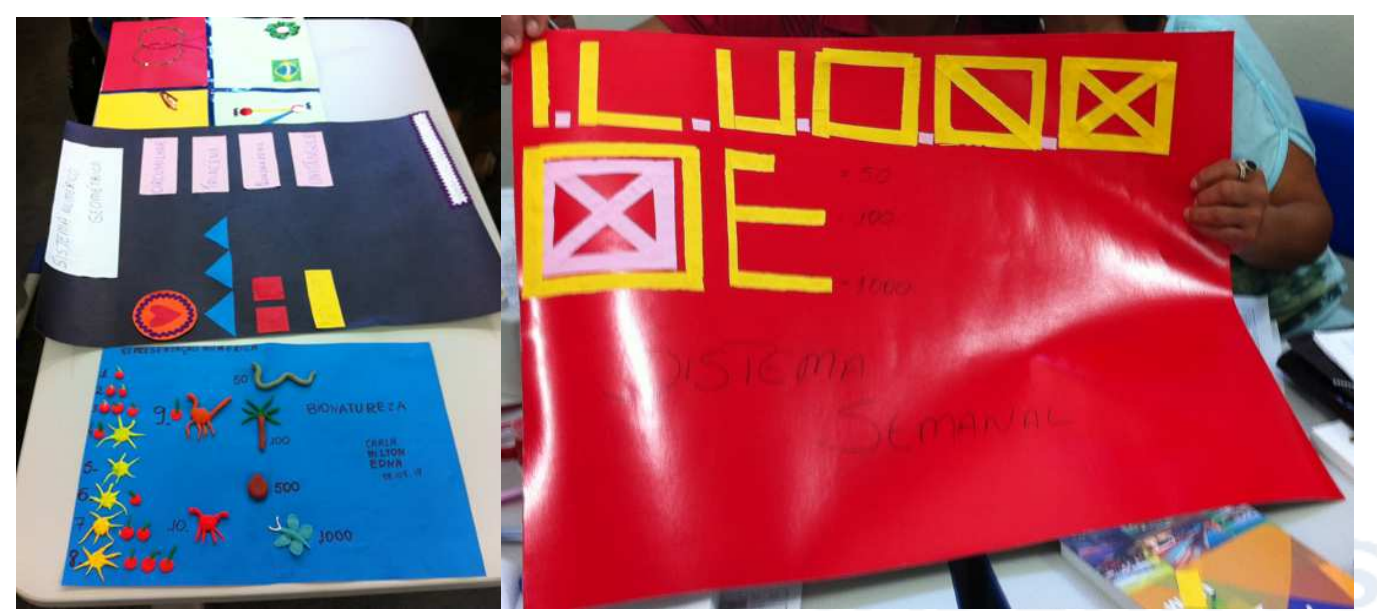

Figura 1: (de cima para baixo e da esquerda para a direita): sistema de numeração "do campo", "geométrico", "bionatureza" e "semanal"

Destaque-se que os estudantes foram incentivados a efetuarem registros de suas produções utilizando câmeras presentes em dispositivos móveis, socializando-as com a turma e, a posteriori, empregar tais registros na elaboração de seu portfólio. Uma vez definidos os símbolos, a próxima etapa foi o desafio de criar uma representação para ausência de elementos (zero), sendo que nenhum outro símbolo poderia ser criado, visto que a base já estava definida.

Em um momento de reflexão coletiva sobre as ideias do texto lido, bem como as produções desenvolvidas, houve discussão sobre o fato de que os sistemas de numeração, como construção coletiva e social, portanto humana, podem ser desenvolvidos por cada um de nós. Buscaram, também, uma relação dessa construção cultural com os conhecimentos práticos da cultura popular, uma vez que todos os sistemas de numeração construídos fazem menção a elementos do campo ou do cotidiano.

Nesse contexto, faz-se necessário distinguir, retomando as ideias iniciais presentes neste texto, uma escola no campo e uma escola do campo, uma vez 
que o primeiro conceito remete a uma educação efetivada na zona rural, na maioria das vezes reproduzindo práticas educacionais já ocorrentes em escolas urbanas. O construto educação do campo, no entanto, reflete uma educação voltada aos atores sociais que vivem no campo, educação diferenciada que atenda às demandas desta população, com métodos e formas de lidar com esta realidade de uma forma especial. De acordo com Caldart (2010, p.67):

Os educadores e as educadoras das escolas do campo vão descobrindo que são mais que alfabetizadores quando alfabetizam, mais do que ensinantes quando ensinam. Eles e elas fazem parte também de uma dinâmica social, cultural e formadora extremamente rica que dá às suas práticas novos sentidos.

A esse respeito, a articulação "Por Uma Educação do Campo", desenvolvida pelos Movimentos Sociais, trouxe à sociedade uma reflexão que se firmou a partir dos anos 1980, conforme mencionado. Esta aponta para políticas públicas de educação do campo que garantam o acesso desde a préescola até a educação superior, e que a escola seja do campo e no campo, que os processos pedagógicos atendam às características camponesas e não urbanas. A articulação em tela também pontuou a necessidade de que os programas de formação docente possam preparar educadores que eduquem para a vida. Nela, também, os educadores são mais que professores e a escola é mais do que escolarização, havendo a defesa da construção pedagógica de uma educação do campo no campo. Esse movimento continua tendo em vista garantir que governos assumam a implementação de políticas públicas voltadas ao acesso e à permanência dos cidadãos do campo na Educação Básica, bem como formação permanente para os/as professores/as, além da Educação de Jovens e Adultos e uma política de Educação Superior (CALDART; PALUDO; DOLL, 2006): algumas dessas ações começam a tomar corpo e se efetivam, a exemplo do que foi relatado nesta seção. 


\section{CONSIDERAÇÕES: FINAIS?}

O movimento "Por uma Educação do Campo" defendeu a existência de políticas públicas reais para essa população. Atualmente são desenvolvidos programas para atender a uma parcela da dívida social com a população do campo e incluem ações como o programa Brasil Alfabetizado, voltado para o jovem rural, bem como projetos de formação profissional de nível médio. Busca-se, também, a formação de técnicos jovens e adultos das áreas de Reforma Agrária e cursos superiores específicos de graduação ou pósgraduação, em diversas áreas do conhecimento, qualificando as ações dos sujeitos que vivem e/ou trabalham para a promoção de educação e do desenvolvimento sustentável das comunidades do campo. Sobre essa última possibilidade é que o presente artigo se debruçou, em um primeiro movimento de reflexão essas atividades formativas em Matemática.

Um ponto-chave para a promoção de uma escola do campo de qualidade é ter um projeto político-pedagógico (PPP) que seja voltado às necessidades da população atendida. Para tal, é importante que este seja pensado e elaborado com o auxílio dos próprios interessados. Um PPP que atenda às necessidades da população é aquele que respeita sua realidade e conscientiza seu povo de sua condição social, trazendo alternativas e perspectivas que possibilitem formar um cidadão crítico capaz de lutar para a transformação do mundo ao seu redor (ANTUNES-ROCHA, 2009).

Além de um PPP bem elaborado, é preciso ter recursos humanos engajados e conscientes com a causa, para que possam construí-lo de forma efetiva. Assim, os formadores atuantes nessas propostas de formação docente necessitam de preparo para conhecer e atuar em uma realidade talvez muito diferente da sua e, acima de tudo, deve haver preparo para respeitarem tal realidade: e esse tem sido um desafio constante no grupo da UFTM. De acordo com a autora (p. 18):

[é necessário um] intenso o diálogo entre os atores envolvidos, no sentido de construir uma nova forma de pensar e agir na formação de educadores, revendo e analisando os passos já dados dentro do curso, visando apontar novos caminhos. Em 
outras palavras, o projeto de formação de professores dentro dessa licenciatura constrói-se no próprio ato de fazê-lo acontecer, contando com a participação efetiva de todos os sujeitos envolvidos. A Licenciatura em Educação do Campo vem ocorrendo de modo diferenciado das demais licenciaturas já ofertadas e consolidadas nas universidades em que a proposta se desenvolve e em outras universidades do país. $O$ fato de ser dirigido a um público bem característico em termos de origem, de história, de projeto de vida e de sociedade, com um forte componente de engajamento político, traz consequências para o perfil dos formadores que se ocupam do curso e para o tipo de escolhas que são feitas.

Frente às propostas do Plano Nacional da Formação dos Profissionais da Educação do Campo (BRASIL, 2009) e das Diretrizes Curriculares Nacionais para a Formação de Professores da Educação Básica, o desenho curricular do curso também evidencia o objetivo de preparar educadores para uma atuação profissional que transcende a docência: inclui a gestão dos processos educativos que acontecem na escola e no entorno dela. Esses educadores estariam, portanto, habilitados ao trabalho na gestão de processos educativos escolares e não-escolares, na construção do projeto políticopedagógico e na organização do trabalho escolar e pedagógico nas escolas do campo. Os conteúdos curriculares sistematizados para essa formação em oito períodos privilegiam conteúdos específicos da área de conhecimento, conteúdos de formação pedagógica, temáticas sobre a Educação do Campo e a relação do homem com a terra, que se refletem no estágio supervisionado.

Destaque-se que o debate sobre as políticas públicas em educação deve considerar a realização de avaliações constantes e daí a necessidade do desenvolvimento de estudos que equacionem as distorções e indiquem caminhos; pesquisas que identifiquem lacunas, levantem os "nós" atuais de práticas que se foram cristalizando: e as interfaces existentes entre a educação do campo e a educação matemática apontam mudanças nesse atual cenário. 


\section{REFERÊNCIAS BIBLIOGRÁFICAS}

ANTUNES-ROCHA, M. I. Licenciatura em Educação do Campo: histórico e projeto político-pedagógico. In: ANTUNES-ROCHA, M.I.I; MARTINS, A. A. Educação do Campo: desafios para a formação de professores. Belo Horizonte, MG, Editora Autentica, 2009, p. 39-57.

ARROYO, M. G.; FERNANDES, B. M. A educação básica e o movimento social do campo. São Paulo: Peres, 1999.

BRASIL. Ministério de Educação. Diretrizes operacionais para a educação básica nas escolas do campo. Brasília, DF, 2002.

. MEC/INEP. PNERA 2004: sinopse estatística da pesquisa nacional da educação na reforma agrária. Brasília DF: MEC, 2007.

- Ministério da Educação. Relatório de referencia da Educação do Campo. Brasília, DF, 2008, 29p.

- Ministério da Educação. Plano Nacional de Formação dos Profissionais da Educação do Campo. Brasília, DF, 2009, 35p.

. Ministério da Educação. Instituto Nacional de Estudos e Pesquisas

Educacionais Anísio Teixeira. Censo Escolar da Educação Básica de 2012:

dados preliminares. Disponível em

$<$ http://portal.inep.gov.br/web/guest/basica-censo >. Acesso em 2 mai. 2014.

. Ministério do Desenvolvimento Agrário. Instituto Nacional de Colonização e Reforma Agrária. Programa Nacional de Educação na

Reforma Agrária: apresentação. Disponível em

<http://www.incra.gov.br/proneraeducacao >. Acesso em 22 jul. 2014.

CALDART, R.S. A escola do campo em movimento. Currículo sem Fronteira, v.3, n91, p.60-81. 2003.

. Educação do Campo: notas para uma análise de percurso. In. MOLINA, M.C. (Org.). Educação do Campo e pesquisa II. Brasília: MDA/MEC, 2010, p.65-73.

; PALUDO, C.; DOLL, J. (Orgs.). Como se formam os sujeitos do campo? Idosos, adultos, jovens, crianças e educadores. Brasília: PRONERA: NEAD, 2006.

EVES, H. Introdução a História da Matemática. Campinas, SP: Editora da Unicamp, 2004. 
JUCÁ, R.S.; FARIAS-JR, L.J.; SÁ, P. F. O Sistema de Numeração: uma Experiência Usando a História da Matemática com os Alunos da 6a Série do Ensino Fundamental. In: Seminário Nacional de História da Matemática, 9.

Anais... Disponível em $<$ http://www.each.usp.br/ixsnhm/Anaisixsnhm/Comunicacoes/1 Juc\%C3\%A1 R S Sistema de Numera\%C3\%A7\%C3\%A3o.pdf>. Acesso em 13 ago. 2014.

LIMA, M.E.C.C.; PAULA, H. F.; SANTOS, M.B.L. Ciências da vida e da natureza no curso de Licenciatura em Educação do Campo - UFMG. In: ANTUNES-ROCHA, M.I.I; MARTINS, A. A. (Orgs.) Educação do Campo: desafios para a formação de professores. Belo Horizonte, MG, Editora Autentica, 2009, p. 107-118.

OLIVEIRA, I.S.; LIMA, M.J.T.; LIMA, C.M.T.; ALELUIA, J.M. Construção do conhecimento científico dos professores pertencentes ao campo sergipano: uma experiência de licenciatura inovadora In. MOLINA, M.S. (Org.). Educação do Campo e pesquisa II. Brasília: MDA/MEC, 2010.

PIO, J.M. Apropriação da escrita no contexto da formação de professores de ciências na educação do campo. 2011. 98 p. Dissertação (Mestrado em Educação) - Faculdade de Educação, Universidade Federal de Minas Gerais: Belo Horizonte, 2011.

RIBEIRO, M. Educação Rural. In: CALDART, R.S.; PEREIRA, I.B.; ALENTEJANO, P. e FRIGOTTO, G. (Orgs.). Dicionário da Educação do Campo. Rio de Janeiro, São Paulo: Escola Politécnica de Saúde Joaquim Venâncio, Expressão Popular, 2012.

TAFFAREL, C. N. Z.; ESCOBAR, M. O.; JUNIOR, C. L. S.; CARVALHO, M. S.; PERIN, T. F. Licenciatura em educação do campo: avaliação do projeto piloto do curso de licenciatura em educação do campo desenvolvido na FACED/UFBA. [2008]. Data certa não indicada na obra. Disponível em $<$ www2.faced.ufba.br/educacampo/...educacao campo/avaliacao projeto pilot o>>. Acesso em: 01 jun. 2014. 